\title{
DRUG-RELATED PROBLEMS AND ITS PRESCRIBING INDICATORS IN STROKE PATIENTS: A PROSPECTIVE OBSERVATIONAL STUDY
}

\section{DURGA PRASAD THAMMISETTY ${ }^{1 *}$, DIVITI RANGANAYAKULU ${ }^{2}$, DEVANNA NAYAKANTI ${ }^{3}$}

${ }^{1}$ Research Scholar, Department of Pharmaceutical Sciences, Jawaharlal Nehru Technological University Anantapur, Ananthapuramu, Andhra Pradesh, India. ${ }^{2}$ Professor, Department of Pharmacology and Principal, Sri Padmavathi School of Pharmacy, Vaishnavi Nagar, Tiruchanoor, Tirupati, Andhra Pradesh, India. ${ }^{3}$ Professor, Department of Chemistry and Director, Oil Technological and Pharmaceutical Research Institute, Jawaharlal Nehru Technological University Anantapur, Ananthapuramu, Andhra Pradesh, India. Email: tsdurgaprasadphd@gmail.com

Received: 16 December 2020, Revised and Accepted: 21 January 2021

\section{ABSTRACT}

Objective: The objective of the study was to assess the drug-related problems (DRPs) and the World Health Organization (WHO) core prescribing indicators among stroke patients.

Methods: A prospective observational study was conducted among stroke inpatients of Acute Medical Care and General Medicine Department of a tertiary care hospital located in Tirupati, Andhra Pradesh, India. A suitable data collection form was used to collect the data about demographics, clinical characteristics, WHO prescribing indicators, and DRPs. Descriptive statistics were used to represent the demographics, distribution of DRPs, and prescribing indicators in the study. Chi-square test was employed to test the significant association between the demographics and the occurrence of DRPs.

Results: Among 174 patients included in the study, 89 had one or more DRPs. A total of 122 DRPs were identified in the study population. Drug interactions (48.4\%) and adverse drug reactions (ADRs) (17.2\%) were commonly observed DRPs. A significant direct association was observed between the occurrence of DRPs and number of comorbidities $(\mathrm{p}<0.001)$, polypharmacy $(\mathrm{p}<0.001)$, and hospital stay ( $<<0.05)$. The average number of drugs per prescription was 7.2. Of drugs prescribed, $67.6 \%$ were in their generic names. The percentage of encounters in which an antibiotic, injection was prescribed was $65.5 \%$ and $89.6 \%$ respectively. The percentage of drugs prescribed from an essential drug list was $91.2 \%$.

Conclusion: The rate of drug interactions and ADRs was high in treatment of stroke patients. Patients suffering from comorbidities, polypharmacy, and long hospital stay were positively associated with occurrence of DRPs in stroke. Regular monitoring and screening for drug interactions and ADRs were advised to reduce the burden DRPs in stroke patients admitted in a critical care unit.

Keywords: Stroke, Prescribing pattern, World Health Organization, Drug use indicators, Drug-related problems.

(C) 2021 The Authors. Published by Innovare Academic Sciences Pvt Ltd. This is an open access article under the CC BY license (http://creativecommons.org/ licenses/by/4.0/) DOI: http://dx.doi.org/10.22159/ajpcr.2021v14i3.40529. Journal homepage: https://innovareacademics.in/journals/index.php/ajpcr

\section{INTRODUCTION}

Ensuring patients' safety has always been an important element of health and medical care for patients in any health-care settings. Studies showed that more than $50 \%$ of all medicines are prescribed, dispensed, or sold inappropriately, while $50 \%$ of patients fail to take them correctly worldwide [1]. Moreover, about one-third of the population worldwide lacks access to essential medicines. Polypharmacy and failure to prescribe in accordance with clinical guidelines are some of the irrational practices in the use of drugs. Irrational use of drugs can result in increasing the morbidity and mortality rates especially in chronic disease patients, waste of resources; increasing out-of-pocket expenses to the patients; and adverse drug reactions (ADRs) [2,3]. The World Health Organization (WHO)-International Network for the Rational Use of Drugs (INRUD) developed a set of core drug use indicators that are useful for studying patterns of drug prescribing in health-care facilities and to measure the rational use of drugs $[4,5]$. Assessment of drug-related problems (DRPs) is a very significant topic in the pharmaceutical field, which would aid to resolve the consequences caused by negative drug therapy. The purpose of identifying DRPs is to help patients to reach their goals of therapy and to achieve the best possible outcomes from drug therapy. DRPs have been identified as one of the common in hospitalized patients and can result in morbidity and mortality which also lead to unnecessary expenditure on healthcare costs [6,7]. Hepler and Strand classified DRPs into eight different categories; including untreated indications, subtherapeutic dosage, excessive dosage, and drug use without an indication, failure to receive drugs, improper drug selection, ADRs, and drug interactions [8]. Stroke, a serious life-threatening medical condition, is the second most common cause of mortality worldwide and is the leading cause of long-term disability in adults, with $90 \%$ of survivors having residual deficits. The incidence of stroke increases with age (especially after age 55 or older), obesity, hypertension, diabetes mellitus, atrial fibrillation, and dyslipidemia $[9,10]$. Stroke patients may be at an increased risk of DRPs. This is partially a result of advanced age, high prevalence of comorbidities, the severity of the disease, and the use of multiple drugs, many of which are high-risk medications including medications used in stroke prevention [11]. The primary aim of this study was to assess the prescribing patterns of medications based on the WHO-INRUD core prescribing indicators and to investigate the characteristics and frequency of DRPs among stroke patients admitted in a tertiary care teaching hospital.

\section{METHODS}

Study design and ethical considerations

A prospective observational study was conducted among the stroke inpatients of the Acute Medical Care Unit and General Medicine Department of a tertiary care hospital located in Tirupati, Andhra Pradesh, India. The study was carried out for a period of 6 months from July 2018 to December 2018. The study proposal and consent process were cleared by the Institutional Ethics Committee (SPSP/2018-2019/ PHD01) before the start of the study. 


\section{Study criteria}

Patients aged 18 years or above, irrespective of gender, and suffering with or without comorbid conditions were included in this study. Patients admitted in an intensive care unit, or taking treatment on outpatient or ambulatory basis, and who are not willing to participate were excluded from this study.

\section{Sample size and sampling}

The required sample size was determined using Epi-info 7 statistical software, given by the center for disease control, USA. The sample size was estimated as 150 by considering $74.1 \%$ of DRPs reported in the previous evidence, design effect $1 \%$, cluster $1 \%$, power $80 \%$, a margin of error $6 \%$, and confidence level $95 \%$

\section{Data collection}

Patients' demographics, clinical characteristics, medication details, and DRPs were collected using a structured format from the medical records and through interviews. Hepler and Strands classification of DRPs 1990 (Hepler and Strand, 1990) was used to categorize the DRPs. The information collected was analyzed to identify DRPs. The collected data were subjected to assess the WHO prescribing indicators such as average number of drugs per prescription, percentage of drugs prescribed by generic name, percentage of encounters with an injection prescribed, percentage of encounters with an antibiotic prescribed, and percentage of drugs prescribed from the essential drug list (EDL).

\section{Data analysis}

The collected data were analyzed using Social Sciences version 23.0 (SPSS $^{\text {мм }}$, Chicago, IL, USA). Descriptive statistics such as mean, standard deviation, frequency, and percentage were used to represent the demographics, distribution of DRPs, and prescribing indicators in the study. Chi-square test was employed to test for the significant association between the age of patients, as well as the gender, locality of patients, comorbidities, length of hospital stay, and the number of drugs toward getting DRPs. The findings are considered as statistically significant association if $\mathrm{p}<0.05$.

\section{RESULTS}

During the 6 months study period, a total of 174 patients who met study criteria were enrolled in this study. The mean age of study subjects was $58.9 \pm 13.2$, and most of the patients belong to the age category of above 60 years. The study findings showed that the majority of the study subjects were males $(115 ; 66.1 \%)$, residing in a rural location (83; $47.1 \%)$, suffering from at least one comorbidity ( $89 ; 51.1 \%)$, prescribed with 5 to 8 number of drugs (134; 77.0\%), and diagnosed with ischemic stroke $(143 ; 82.2 \%)$. The detailed demographics are shown in Table 1.

Among 174 patients, 89 were suffered from one or more DRPs. A total of 122 DRPs was identified and, the most common was drug interactions, accounting for $48.4 \%$ of the total DRPs, followed by an ADR in $17.2 \%$ of the patients. Table 2 represents the different types of DRPs and drugs involved.

Independent factors that predicted the occurrence of DRPs in the study population were age, gender, location, average number of drugs, number of comorbidities, and length of hospital stay were evaluated to determine whether they could predict the occurrence of DRPs or not. The result showed that association was observed between the presence of more than one comorbidity $(\mathrm{p}<0.001)$, polypharmacy $(\mathrm{p}<0.001)$, and length of hospital stay $(\mathrm{p}<0.05)$ with the occurrence of DRPs. Correlation between the demographic features and DRPs is shown in Table 3.

Assessment of the WHO-INURD indicators had revealed that an average of 7.2 drugs prescribed per patient. The percentage of drugs prescribed by their generic names was $67.6 \%$. The percentage of encounters with antibiotics was $65.5 \%$. The percentage of encounters with the injections was $89.6 \%$ and $91.2 \%$ of drugs prescribed were from EDL/formulary. Distribution of the WHO prescribing indicators among the study population and their standard values are represented in Table 4

\section{DISCUSSION}

The WHO core indicators of prescribing practices measure the performance of health-care providers in key dimensions related to the appropriate use of drugs. Hence, this study was aimed to analyze the prescribing indicator among stroke patients which will help to promote the rational use of drugs, which improves the quality of treatment and achieve definite outcomes. In our study, the average number of drugs per encounter was 7.2, which was far more when compared with the standard WHO recommended value of 1.6-1.8. Polypharmacy leads to many consequences such as ADRs, drug-drug interactions leading to therapeutic failure or toxicity, reduces patient compliance, unnecessary drug expenses, and risk of emergence of bacterial resistance in case if antibiotics from different classes are prescribed for the same patient without rationale [12]. Our study findings revealed that there was a high proportion of prescribing of injections, and antibiotics among stroke patients in reference with the WHO standards. Even though stroke patients require critical care, where there was a high use of antibiotics and injections, still there was a need to develop critical care guidelines to reduce the high use of antibiotics and injections. This will reduce the antimicrobial resistance and injection site reaction/adverse events. The WHO suggests all medical practitioners to prescribe drugs in generic name and from the essential medicine list. However, our study findings are not as per the norms of the WHO standards. At the study center, all the physicians were encouraged to follow the standard guidelines to reduce the risk of dispensing errors and the cost of the prescription. Out of 89 patients who had developed DRPs, the majority of DRPs occurred in males 62 (53.9\%) as compared to females 27 (45.8) which is consistent with the earlier study conducted by Ramanath and Nedumballi [13]. Drug interactions (48.4\%) and ADRs (17.2\%) were the most common DRPs reported in the current stroke study. The results were similar with findings of the study conducted by Greeshma et al. in South Indian hospital [14]. The high rate of drug interactions found in this study may due to a greater number of drugs and inappropriate combination of prescribed drugs. Regular monitoring and screening for the drug interactions and ADRs were advised to reduce the burden DRPs in stroke patients admitted in critical care unit. Comorbidities are associated with multiple medications therapy which, in turn, increases the risk of occurrence of DRPs in stroke patients. In the current study, occurrence of DRPs was found to be high in patients with more than

Table 1: Demographics and characteristics of study population $(n=174)$

\begin{tabular}{ll}
\hline Variable & Number (\%) \\
\hline Gender & $115(66.1)$ \\
Male & $59(33.9)$ \\
Female & $58.9 \pm 13.2$ \\
Age in year (Mean \pm SD) & $21(12.1)$ \\
18-40 & $70(40.2)$ \\
$41-60$ & $83(47.7)$ \\
$>60$ & \\
Residence & $152(87.4)$ \\
Rural & $22(12.6)$ \\
Urban & \\
Comorbidities & $85(48.9)$ \\
None & $42(24.1)$ \\
1 & $44(25.3)$ \\
2 & $3(1.7)$ \\
3 & $134(77.0)$ \\
No of Drugs/Prescription & $40(23.0)$ \\
5-8 & \\
>8 & $143(82.2)$ \\
Type of stroke & $31(17.8)$ \\
Ischemic stroke & \\
Hemorrhagic stroke & \\
\hline SD: Standard deviation &
\end{tabular}


Table 2: Distribution of drug-related problems identified in the study population $(n=174)$

\begin{tabular}{|c|c|c|}
\hline Drug-related problems & Number (\%) & Drugs Involved \\
\hline Drug use without indication & $10(8.2)$ & Metformin, Gabapentin, Pantoprazole, Metoclopramide \\
\hline Untreated indication & $9(7.4)$ & Hypertension, Anemia, Constipation, Breathlessness, Hypokalemia, and Diarrhea \\
\hline Improper drug selection & $5(4.1)$ & $\begin{array}{l}\text { Inappropriate drug according kidney function-Tramadol, inappropriate drug according } \\
\text { Liver function - paracetamol, drugs that should be avoided in the elderly - diazepam, and } \\
\text { hydroxyzine }\end{array}$ \\
\hline Sub-therapeutic dosage & 7 (5.7) & $\begin{array}{l}\text { Inappropriately low dosage based on patient's condition-insulin, atenolol, furosemide, } \\
\text { atorvastatin }\end{array}$ \\
\hline Failure to receive drugs & 7 (5.7) & $\begin{array}{l}\text { Loss to follow-up - atorvastatin, losartan } \\
\text { Self-discontinuation due to lack of understanding on the importance of secondary } \\
\text { prevention drugs - aspirin, atorvastatin, and metformin }\end{array}$ \\
\hline Drug interaction & $59(48.4)$ & $\begin{array}{l}\text { Enalapril+Furosemide - Postural Hypotension } \\
\text { Losartan+Aldactone - Increased risk of Hyperkalemia } \\
\text { Salbutamol+Ondansetron - Increased Risk of Arrhythmias } \\
\text { Pantoprazole+Propranolol - Increase Propranolol exposure }\end{array}$ \\
\hline
\end{tabular}

Table 3: Correlation between patient characteristics and drug-related problems $(n=174)$

\begin{tabular}{lllll}
\hline Variable & Total (n=174) & DRPs & Chi-square & p value \\
\hline $\begin{array}{l}\text { Age (years) } \\
>60\end{array}$ & $83(47.7)$ & $42(50.6)$ & 0.0189 & 0.89060 \\
$\quad<60$ & $91(52.3)$ & $47(51.6)$ & & \\
$\begin{array}{l}\text { Gender } \\
\quad \text { Male }\end{array}$ & $115(66.1)$ & $62(53.9)$ & 1.0307 & 0.30990 \\
$\quad \begin{array}{l}\text { Female } \\
\text { Location }\end{array}$ & $59(33.9)$ & $27(45.7)$ & & \\
$\quad$ Rural & $152(87.3)$ & $74(48.6)$ & 2.9071 & 0.08810 \\
$\quad$ Urban & $22(12.6)$ & $15(68.2)$ & & \\
$\begin{array}{l}\text { Comorbidities } \\
>1\end{array}$ & $47(27.0)$ & $36(76.6)$ & 16.591 & $<0.001$ \\
$\quad 127(72.9)$ & $53(41.7)$ & & \\
$\quad$ No. of drugs & & & & \\
$\quad>8$ & $40(22.9)$ & $34(85.0)$ & 23.682 & $<0.001$ \\
$\quad \leq 8$ & $134(77.0)$ & $55(41.0)$ & & \\
Hospital stays & & & & \\
$>5$ days & $95(54.6)$ & $58(61.0)$ & 8.1655 & $<0.001$ \\
$\quad \leq 5$ days & $79(45.4)$ & $31(39.2)$ & & \\
\hline DRP: Drug-related problem & & &
\end{tabular}

Table 4: Distribution of the WHO core prescribing indicators among stroke patients $(n=174)$

\begin{tabular}{lll}
\hline Indicator & Average/Percentage & $\begin{array}{l}\text { WHO standard } \\
\text { derived or } \\
\text { ideal (\%) }\end{array}$ \\
\hline $\begin{array}{l}\text { Average number of } \\
\text { drugs per encounter }\end{array}$ & 7.2 & $1.6-1.8$ \\
$\begin{array}{l}\text { Percentage of drugs } \\
\text { prescribed by generic }\end{array}$ & 67.6 & $20.0-26.8$ \\
$\begin{array}{l}\text { name } \\
\text { Percentage of } \\
\text { encounters prescribed } \\
\text { with an antibiotic }\end{array}$ & 65.5 & $13.4-14.1$ \\
$\begin{array}{l}\text { Percentage of } \\
\text { encounters prescribed } \\
\text { with an injection }\end{array}$ & 89.6 & 100 \\
$\begin{array}{l}\text { Percentage of drugs } \\
\text { prescribed from }\end{array}$ & 91.2 & 100 \\
EDL/Formulary & & \\
\hline EDL: Essentaldrug list, WH0: World & & \\
\hline
\end{tabular}

EDL: Essential drug list, WHO: World Health Organization
1 comorbid condition. It revealed that the patient who has comorbidities has increased risk of developing DRPs with a $p<0.001$. The results were similar with a study conducted by Ahmad et al. [15]. Incidence of drug interactions will be more with the increased number of drugs in a prescription. The same association was observed with the number of drugs in the prescription and the risk of DRP with a $p<0.001$. These results were similar to the study published by Abdela et al., in which the patients with polypharmacy $(2.748 ; 1.544-4.889)$ were associated with increased risk of DRPs [16]. The length of hospital stay may depend on the severity of the disease, ineffective drug use, and DRPs; in this study, we observed a greater number of DRPs in patients who stayed more days in the hospital $(\mathrm{p}<0.001)$.

\section{Strengths and limitations}

The study provides major insights for resolving various types of DRPs occurred in stroke patients. This is the primary study that observed rationality of prescribing using the WHO core prescribing indicators. The findings of our study are not extrapolated to stroke patients who are taking medication on out-patient, in-patient, and ambulatory basis. By taking this as a limitation, findings need to be interpreted in developing policies or procedures to control DRPs.

\section{CONCLUSION}

The study concludes that the rate of drug interactions and ADRs was high in treatment of stroke patients. Patients suffering with comorbidities, advised a greater number of drugs, and hospital stay was positively associated with occurrence of DRPs in stroke. The study suggests physicians to comply with the WHO prescribing indicators to improve the outcomes and to reduce the DRPs. Clinical pharmacist needs to work with critical care team in tailoring the prescription and to improve the outcomes of the stroke patients.

\section{ACKNOWLEDGMENT}

The authors would like to thank the participants involved the study for providing all types of information in bringing completion of the work. The authors also wholeheartedly thankful to the medical superintendent and HOD of the General Medicine Department of the hospital for supporting this study.

\section{AUTHORS' CONTRIBUTIONS}

All authors contributed to the conception, design, interpretation, and compilation of results, and execution of the study. The corresponding 
author drafted the manuscript, and incorporated the suggestions from other authors.

\section{CONFLICTS OF INTEREST}

The authors declared no conflicts of interest in this work.

\section{FUNDING}

All authors had declared that they did not receive any funding from government or private or any other organizations.

\section{REFERENCES}

1. Ofori-Asenso R, Agyeman AA. Irrational use of medicines a summary of key concepts. Pharmacy (Basel, Switzerland) 2016;4:35

2. World Health Organization. Promoting Rational Use of Medicines: Core Components WHO Policy Perspectives on Medicines. Geneva, Switzerland: World Health Organization; 2002. Available from: http:// www.apps.who.int/medicinedocs/en/d/Jh3011e/2.html. [Last accessed on 2020 Dec].

3. Imran A. Irrational Use of Medicine-a Threat to Patient Community. Available from: https://www.ezinearticles.com/?irrational-use-ofmedicines---a-threat-to-patient-community\&id=3144554. [Last accessed on 2020 Dec].

4. World Health Organization. How to Investigate Drug Use in Health Facilities: Selected Drug Use Indicators. Geneva, Switzerland: World Health Organization; 1993. Available from: http://www.apps.who.int/ medicinedocs/en/d/Js2289e/1993. [Last accessed on $2020 \mathrm{Dec}$ ].

5. World Health Organization. Operational Package for Assessing, Monitoring and Evaluating Country Pharmaceutical Situations: Guide for Coordinators and Data Collectors. Geneva, Switzerland: World Health Organization; 2007. Available from: https://www.who.int/ medicines/publications/WHO TCM 2007.2/en. [Last accessed on 2020 Dec]
6. Strand L, Cipolla R, Morley P. Pharmaceutical Care Practice: The Patient-Centered Approach to Medication Management. $3^{\text {rd }}$ ed. New York: McGraw-Hill; 2012. p. 435-44.

7. Semcharoen K, Supornpun S, Nathisuwan S, Kongwatcharapong J. Characteristic of drug-related problems and pharmacists' interventions in a stroke unit in Thailand. Int J Clin Pharm 2019;41:880-7.

8. Hepler CD, Strand LM. Opportunities and responsibilities in pharmaceutical care. Am J Hosp Pharm 1990;47:533-43.

9. Marie A, Chisholm B, Jerryl S, Barbara GW, Dipiro JT. Pharmacotherapy Principles and Practice. $2^{\text {nd }}$ ed. New York: McGraw-Hill; 2010. p. 215-6.

10. Banerjee TK, Roy MK, Bhoi KK. Is stroke increasing in India-preventive measures that need to be implemented. J Indian Med Assoc 2005;103:162-4, 166 passim.

11. Hanlon JT, Semla TP, Schmader KE. Alternative medications for medications in the use of high-risk medications in the elderly and potentially harmful drug-disease interactions in the elderly quality measures. J Am Geriatr Soc 2015;63:1-11.

12. Ragam A, Acharya S, Holla R. Assessment of drug use pattern using World Health Organization prescribing indicators in a tertiary care hospital in Mangalore: A cross-sectional study. Natl J Physiol Pharm Pharmacol 2017;7:1026-30.

13. Ramanath KV, Nedumballi S. Assessment of medication-related problems in geriatric patients of a rural tertiary care hospital. J Young Pharm 2012;4:273-8

14. Greeshma M, Lincy S, Maheswari E, Tharanath S, Viswam S. Identification of drug related problems by clinical pharmacist in prescriptions with polypharmacy: A prospective interventional study. $\mathrm{J}$ Young Pharm 2018;10:460-5.

15. Ahmad A, Mast MR, Nijpels G, Elders PJ, Dekker JM, Hugtenburg JG. Identification of drug-related problems of elderly patients discharged from hospital. Patient Prefer Adherence 2014;8:155-65.

16. Abdela OA, Bhagavathula AS, Getachew H, Kelifa Y. Risk factors for developing drug-related problems in patients with cardiovascular diseases attending Gondar University Hospital, Ethiopia. J Pharm Bioall Sci 2016;8:289-95. 